\title{
La vocación no directiva de Carl Rogers: teoría, psicoterapia y relaciones de poder
}

The Non-Directive Vocation of Carl Rogers: Theory, Psychotherapy and Relations of Power

La vocation non directive de Carl Rogers : théorie, psychothérapie et relations de pouvoir

\section{Areli Vázquez Arellano y Raúl Ernesto García Rodríguez}

\section{OpenEdition}

\section{Journals}

Edición electrónica

URL: https://journals.openedition.org/rccs/12053

DOI: $10.4000 /$ rccs. 12053

ISSN: 2182-7435

Editor

Centro de Estudos Sociais da Universidade de Coimbra

Edición impresa

Fecha de publicación: 1 septiembre 2021

Paginación: 77-98

ISSN: 0254-1106

Referencia electrónica

Areli Vázquez Arellano y Raúl Ernesto García Rodríguez, «La vocación no directiva de Carl Rogers: teoría, psicoterapia y relaciones de poder», Revista Crítica de Ciências Sociais [En línea], 125 | 2021,

Publicado el 30 septiembre 2021, consultado el 03 octubre 2021. URL: http://journals.openedition.org/ rccs/12053 ; DOI: https://doi.org/10.4000/rccs.12053 


\title{
ARELI VÁZQUEZ ARELLANO, RAÚL ERNESTO GARCÍA RODRÍGUEZ
}

\section{La vocación no directiva de Carl Rogers: teoría, psicoterapia y relaciones de poder}

\begin{abstract}
En el presente artículo se realiza una breve presentación y una revisión crítica de algunas de las ideas más importantes del pensamiento de Carl Rogers en relación con su concepción y su práctica de la psicoterapia. Así, desde un ejercicio interpretativo sustentado en planteamientos de la psicología crítica y sin pretender hacer afirmaciones absolutas, se cuestionan varios postulados de la perspectiva rogeriana en su contexto histórico-teórico y en su vínculo consustancial con las relaciones de poder que presuponen y que reproducen en su desarrollo. En todo caso, se discute también el ejercicio de la psicologización presente en el dispositivo rogeriano, su carácter político y su tendencia a la armonización acrítica de las relaciones sociales.
\end{abstract}

Palabras-clave: Carl Rogers; pensamiento crítico; psicoterapia; relaciones de poder; relaciones sociales.

Palavras-chave: Carl Rogers; pensamento crítico; psicoterapia; relações de poder; relações sociais.

\section{Contexto histórico-teórico de la obra de Carl Rogers y su presencia en la psicología humanística}

La obra del psicólogo y psicoterapeuta Carl Ransom Rogers contribuyó de modo crucial a la instauración y proyección de la psicología humanista. El desarrollo del pensamiento teórico y profesional de Rogers se encuentra esclarecido particularmente en sus libros Psicoterapia centrada en el cliente (1997 [1951]), Terapia, personalidad y relaciones interpersonales (2007 [1959]) y El proceso de convertirse en persona (2011 [1961]), que fueron escritos en diferentes momentos y contextos de su vida y bajo la influencia de su propia filosofía personal, tal como él mismo llega a describir.

Los comienzos de sus estudios universitarios están en el campo de la agricultura científica, en la Universidad de Wisconsin, que después de dos años abandonaría. Este vuelco se da a consecuencia de las conferencias 
religiosas a las que asiste, describiendo la situación como una "intensa resonancia emocional” (Rogers, 2011 [1961]: 18). Esto lo llevó a reorientar sus estudios hacia el campo de la historia, sin olvidar, no obstante, su interés por el ministerio sacerdotal.

En 1922, Rogers realiza un viaje relativamente corto a China con la finalidad de participar en una conferencia internacional de la Federación Cristiana Estudiantil Mundial, donde tiene una experiencia de vida de la que surgirá un nuevo punto de vista acerca de cómo las personas llegan a tener creencias religiosas diversas. Al regreso de la expedición, concluye sus estudios en historia y, seguidamente, iniciará estudios de teología hacia el año 1924, en Nueva York, en el Union Theologycal Seminary. Posteriormente, deja inconclusos sus estudios teológicos para hacer una incursión "inintencionada" en la psicopedagogía, en el Teachers College de la Universidad de Columbia; en un primer momento tomando un curso sobre filosofía de la educación, a propósito de las ideas de John Dewey, impartido por William H. Kilpatrick. Esto da pie a prácticas clínicas con niños, supervisado por Leta Hollingworth, obteniendo conocimientos de psicología clínica y pensándose, desde esa etapa, como psicólogo clínico (Rogers, 2011 [1961]: 18-20).

En su trabajo como interno en la clínica psicopedagógica del Institute For Child Guidance, y al tiempo que prepara el doctorado, se le presenta un conflicto que lo desestabiliza por estar rodeado del pensamiento de Freud, orientación psicoanalítica dinámica contenida y sostenida por los psiquiatras David Levy y Lawson Lowrey. En este contexto, Rogers considera que el instituto presenta un "espíritu altamente especulativo" (2007 [1959]: 9) y lo contrapone con los conocimientos previos del pensamiento de Edward Thorndike.

Más tarde, Rogers se incorpora al Instituto de Orientación Infantil de Rochester, donde laboró durante doce años en un entorno de arduo trabajo práctico e intelectual, incluyendo las actividades que realiza con su equipo. El Departamento de Psicología de la propia Universidad de Rochester, solo se interesaba por los resultados prácticos de los trabajos interventivos con individuos que presentaban inadaptación, principalmente niños y adolescentes, pero también adultos.

Para Rogers, adentrarse en el campo de la psicoterapia no fue un camino fácil, dado que no entró de lleno a esta práctica por ser partidario de la psicología y no tanto de la psiquiatría, ya que, hasta esos momentos, esta última era la única responsable de llevarla a cabo. El nuevo sendero que promueve Rogers tuvo que ser forzado por él mismo a través de las entrevistas que realizaba a sus clientes, a las que denominó entrevistas clínicas. 
La estructura general del pensamiento rogeriano está formada por definiciones de carácter sistémico, es decir, los conceptos que forman parte de su teoría están construidos a partir de conceptos filosóficos, particularmente fenomenológicos y también empírico-analíticos. Según Rogers, dichas afirmaciones teóricas se basan en "conocimientos fundados en pruebas empíricas objetivas” (2011 [1961]: 64). La sistematización de los conceptos teóricos ha contribuido al ordenamiento y reproducción de su pensamiento y de las técnicas terapéuticas, así como a una imparable investigación teórico-práctica, mediante los casos clínicos.

La psicoterapia de Rogers apunta a lograr el "desarrollo psicológico" por medio de un proceso con características propias, de las cuales hace énfasis en la experiencia y en el organismo, constructos cuyo sentido teórico específico sólo se alcanza en el quehacer de la propia psicoterapia. Ambos conceptos son dependientes; en el primero se alude al "campo fenoménico" o "campo experiencial", también conocido como "experiencias viscerales y sensoriales" y/o "experiencias orgánicas", un término que "se usa para englobar todo lo que sucede dentro del organismo en cualquier momento y que está potencialmente disponible para la conciencia" (Rogers, 2007 [1959]: 26). El segundo constructo, es decir, el organismo (experienciante), lo reconoce Rogers en el individuo responsable de su funcionamiento o proceso de desarrollo específico.

A Rogers se le reconoce como el principal impulsor, en psicoterapia, del llamado enfoque centrado en la persona, también conocido como enfoque centrado en el cliente. Su trabajo con grupos, llamado grupos de encuentro, se da de la misma manera que en el proceso de terapia individual, proceso en el cual se procura "facilitar" pero no "dirigir" el desarrollo psicológico del sujeto. Según Rogers todo organismo (incluyendo el grupo que se concibe como tal) contiene la sabiduría en su totalidad, reconociéndola como la sabiduría del organismo mismo, "esta es mi manera de decir que he visto manifestarse 'la sabiduría del organismo' en todos los niveles, desde la célula hasta el grupo". Pero esto no quiere decir que cualquier grupo la desarrolle, o sea, "ello no significa que cualquier grupo logra 'éxito' o que el proceso es idéntico en todos los casos” (Rogers, 2001 [1970]: 52). En consecuencia, el tener éxito en un grupo constituye la experimentación retributiva y satisfactoria, a la cual se refiere como experiencia gratificadora.

Las concepciones de Rogers para el presunto estudio profundo de la conducta humana (una de ellas postulada como "teoría de la personalidad"), parten de la fenomenología para hacer descripciones del desarrollo de la persona. En su libro Psicoterapia centrada en el cliente (1997 [1951]), se habla sobre las influencias que recibió su teoría en el proceso de construcción, 
de tal forma que se estableció un vínculo con las teorías de la personalidad que ya tenían presencia entre los años 1940 y 1950. De acuerdo con esto se menciona a Andras Angyal, con "la teoría de sistemas" de 1941; a Abraham Maslow, con su "teoría sobre la motivación humana" de 1943: a Gardner Murphy, con su libro titulado Personalidad, de 1947, en el cual postula la "teoría biosocial de la personalidad", y a Harry Sullivan (con su obra de 1953 y su "teoría interpersonal en la psiquiatría", entre otros autores (Rogers, 1997 [1951]: 409).

En otra de sus concepciones, Rogers habla, por un lado, de la llamada "teoría terapéutica" y de la modificación de la personalidad como proceso de mejoría del cliente en todos los aspectos de su vida y, por otro, de la "teoría de las relaciones interpersonales", que permite localizar "el orden fundamental inherente a toda comunicación y a toda relación interpersonal” (Rogers, 2007 [1959]: 85), y que, además, según el propio Rogers, está íntimamente relacionada con la dirección, la jerarquización y el control del poder, lo cual, en última instancia, está vinculado a una dimensión personal. En este sentido, Rogers afirma: "Tradicionalmente, las organizaciones, sean gubernamentales, industriales, educativas o médicas, han sido administradas mediante una distribución jerárquica del poder. En lo más alto de la jerarquía está una persona” (1997 [1951]: 62).

En un punto prominente de su pensamiento, Rogers llega a un momento crítico respecto a su propio trabajo, en el cual retoma todo lo que ha estado aportando a la sociedad, especialmente a la sociedad académica, lo justifica e intenta contrarrestar los cuestionamientos de otros enfoques, principalmente de sus detractores, como la psicología social por un lado y la crítica del psicoanálisis, por el otro. En todo caso, el pensamiento rogeriano influye en la psicología misma y en las personas que se someten a su modelo psicoterapéutico.

En sus investigaciones sobre lo educativo Rogers (Rogers y Rosenberg, 1989 [1977]) hace uso del término política. En este sentido, se afirma que dicha palabra tiene que ver con:

El poder o control en las relaciones interpersonales y con la medida en que las personas se esfuerzan por conseguir este poder o para renunciar a él. Tiene que ver con las tácticas o estrategias mediante las cuales las personas ejercen control unas sobre otras o delegan tal poder. Tiene que ver con la manera como se toman las decisiones. ¿Quién las toma? ¿Dónde está el locus o centro del poder de decisión? Tiene que ver con los efectos sobre individuos o sistemas de esas acciones orientadas hacia el poder (ibidem: 151). 
Esta reflexión revela que Rogers se interesó por la cuestión del poder, aunque, como veremos, dicha noción quedará circunscrita, en última instancia, al ámbito psicológico-personal.

En lo referente a la cuestión educativa (proceso de aprendizaje), Rogers reivindica la posibilidad de un espacio para el aprendizaje centrado en la persona y en esa lógica se valoran las vivencias y el rol del aprendiz y del facilitador, y se intenta describir las características que corresponden a cada uno de los implicados (persona facilitadora, estudiante, padres o miembros de una comunidad) en el funcionamiento del propio proceso de aprendizaje de los eventuales centros institucionales respectivos (escuela alternativa o universidad abierta). Respecto a lo anterior, la política educativa que propone Rogers se constituye desde una posición centrada en la persona; de este modo, "en este tipo de enseñanza la persona que está creciendo y aprendiendo representa una fuerza política poderosa. El aprendiz es el centro" (Rogers y Rosenberg, 1989 [1977]: 155-157).

En cualquier caso, la intención de este artículo es, ante todo, reflexionar sobre el pensamiento rogeriano y su tendencia a la psicologización de la vida social; revisar a grandes rasgos sus concepciones y su importancia para el quehacer psicoterapéutico, y, en esta lógica, presentar una crítica al carácter interventivo y a la manera en que se establecen las relaciones de poder en el modelo terapéutico humanista, desde una mirada política más amplia.

\section{El pensamiento rogeriano y las relaciones de poder en la psicoterapia no directiva}

Carl Rogers constituye uno de los exponentes fundamentales de la llamada "tercera fuerza" en psicología y en psicoterapia. Sus concepciones teóricas, derivadas de su práctica profesional y de la asunción de referentes filosóficos de carácter fenomenológico y existencialista se convierten, junto a otras elaboraciones de diversos autores, en una propuesta que alterna y disiente respecto a las vertientes psicoanalíticas y conductuales. Es así que, desde mediados del siglo xx, Rogers fue configurando un sistema de intervención psicológica que se desarrolla, al principio y ante todo, en el ámbito de la psicoterapia individual y el "asesoramiento centrado en el cliente", pero que pronto se extiende al mundo de la dinámica de grupo para incursionar significativamente en los llamados grupos de encuentro. La influencia de Rogers en el quehacer de la psicología se reconoce ampliamente porque además aplicó sus concepciones y procedimientos en el trabajo terapéutico con familias y en el terreno de la educación y el aprendizaje.

Según la teoría de Rogers (2001 [1970]), el individuo vive inmerso en un "campo fenoménico" constituido por el cúmulo de experiencias que 
dicha persona vivencia en relación con el mundo, con los demás y consigo mismo. El sujeto es el centro de este "campo experiencial" cambiante que deviene en una especie de mundo privado para ese sujeto. De ese conjunto enorme y constante de experiencias dinámicas, solo una porción reducida se vive conscientemente. La concientización se relaciona con la posibilidad de "simbolizar" algunas de las experiencias que tiene esa persona. Aunque haya experiencias que en determinado momento no son simbolizadas, estas tienen la propiedad de ser accesibles a la consciencia si tales experiencias se asocian con el proceso de satisfacción de necesidades en el sujeto. Sucede que el individuo reacciona ante ese "mundo privado" tal como él lo vivencia y lo percibe. El campo experiencial, el ámbito perceptual de la persona, es para ese individuo la realidad, porque es $s u$ realidad. La persona se mueve siempre en relación a la percepción que tiene de la realidad y a las experiencias que surgen de ese vínculo. El comportamiento de todo individuo se adscribe a la realidad tal como este la percibe. Rogers afirma: "Vivimos en un 'mapa' perceptual que nunca es la realidad misma [...] A los fines de la comprensión de los fenómenos psicológicos, la realidad es, para el individuo, su percepción” (2000 [1959]: 196). Desde esta visión, las reacciones del sujeto, en tanto organismo experienciante, ocurrirán siempre como una totalidad organizada en relación a su campo fenoménico. Las respuestas individuales serán propensas al carácter holístico, intencional, sistémico y coherente que se arraiga y se proyecta. No obstante, el núcleo problemático existencial de muchas personas consiste precisamente en que tal condición experiencial puede ser rechazada o negada por la consciencia (por cierto, mediante el proceso de subcepción), situación que, como se verá más adelante, produce escisiones psicológicas que laceran en mayor o menor grado al individuo y afectan sus relaciones con los demás.

Todo ser vivo, contiene e implica un "potencial de crecimiento" de carácter innato, cuya función clave es impulsar al organismo a completarse o realizarse en términos de su propio diseño genético. Tal reflexión toma cuerpo conceptual en la llamada tendencia a la actualización. Rogers puntualiza:

Nos referimos a la tendencia del organismo a mantenerse, a asimilar su aliento, a comportarse defensivamente frente a las amenazas, a lograr la meta de la autopreservación aun cuando el camino usual que conduce a esa meta está bloqueado. Nos referimos a la tendencia del organismo a avanzar en la dirección de maduración, tal como se define para cada especie. Esto implica la autorrealización [...] El organismo se realiza en dirección a una mayor diferenciación de los órganos y las funciones. 
Avanza en dirección a una expansión limitada a través del crecimiento, se expande prolongándose mediante sus instrumentos, y se expande mediante la reproducción. Avanza en dirección a una mayor independencia y autorresponsabilidad (2000 [1959]: 199-200).

En efecto, según Rogers, la tendencia a la actualización promueve un creciente autogobierno, desarrolla procesos de regulación autónoma en el organismo y, de algún modo, se aparta del control o dominio heterónomo que intenten fuerzas externas a él. En el ser humano, la tendencia a la actualización se presenta en forma de necesidades y motivos que orientan su comportamiento hacia la maduración. En este sentido, Gerardo Rodríguez Echeverría y José Velasco Lafarga (2000: 214) afirman: "Rogers reconoce una sola motivación polimorfa a escala del organismo total: la tendencia actualizante. El sistema de Rogers desde este punto de vista es un monismo. Esta tendencia actualizante de base, es la única motivación que postula en su sistema teórico". De esta forma, el ambiente del individuo, su contexto físico y social, interviene sobre el potencial de crecimiento personal solo para fomentarlo u obstaculizarlo. Además -como se verá más adelantela tendencia a la actualización se expresa psicológicamente también en la emergencia del "sí mismo" en el individuo y en su potencial de desarrollo, concebido como "propia actualización”, lo cual, según Rogers, se relaciona con la noción de identidad y de amor propio en la persona.

Por lo tanto, el individuo saludable podrá configurar motivos dirigidos a satisfacer sus potencialidades. Rogers (2000 [1959]: 202) afirma:

El terapeuta toma consciencia de que la tendencia progresiva del organismo humano es la base en la que confía más profunda y fundamentalmente. Se hace evidente no sólo en la tendencia general de los clientes a avanzar en dirección al crecimiento cuando los factores de la situación son claros, sino que se muestra más dramáticamente en casos muy graves en que el individuo está al borde de la psicosis o el suicidio. En estos casos el terapeuta es consciente de que la única fuerza en la que puede confiar básicamente es la tendencia orgánica a continuar el desarrollo.

Aunado a lo anterior, el sujeto desarrolla un sistema regulador del comportamiento, constituido por un proceso de valoración de los objetos y acontecimientos del mundo, congruente respecto a las experiencias y vivencias afectivas que se producen en su persona (sea en el sentido del agrado, la satisfacción o el placer, o sus opuestos). A esto se le denominó proceso de valoración de tipo orgánico, el cual, si es desplegado adecuadamente, propicia en el sujeto elecciones a favor de su bienestar y su desarrollo. 
En el proceso de maduración del sujeto, impulsado por la tendencia actualizante, se presenta una gradual diferenciación del propio individuo respecto al resto del mundo. Esta diferenciación se expresa en el surgimiento del sí mismo (self), es decir, la percepción y las experiencias que el individuo tiene de sí; a su vez, esto implica una escisión de la experiencia total del sujeto que se hace accesible a una simbolización consciente. La aparición del sí mismo es concomitante respecto al surgimiento en el propio individuo de la necesidad de atención positiva por parte de otras personas significativas para él. En virtud de que el individuo está en relación con personas significativas para él, resulta inevitable que tales personas participen en el proceso de valoración de las experiencias del individuo a través de reacciones, opiniones o emociones, que no siempre satisfacen aquella necesidad de atención positiva o de aprobación que tiene el individuo desde la primera infancia. Es decir, los otros influyen en el proceso de evaluación experiencial del individuo, al mismo tiempo que se está configurando su "yo" o autoconcepto.

Es así que el individuo valora sus experiencias, a veces en correspondencia a su apreciación "organísmica" (valoración de tipo orgánico) y a veces en correspondencia a los criterios normativos de los otros significativos, con tal de no perder la atención positiva y la aprobación de estos últimos. Esta situación genera la incorporación por parte del sujeto de una evaluación condicionada de sus experiencias. Se configuran así las llamadas condiciones de valor (o condiciones de valía) constituidas por el conjunto de preceptos, normas y conductas que el individuo debe aceptar y asumir (como propios) si se desea la consideración y el reconocimiento de los demás. El yo adquiere un carácter dual. En otras palabras, tal como señala Dionisio Zaldívar (1991: 238-239):

el sí mismo (autoconcepto) se va conformando en el individuo, a partir de las experiencias evaluadas, tanto de manera condicional como incondicional, es decir, el sí mismo incorpora no solamente experiencias valoradas directamente por el propio individuo, sino también en su conformación influyen las valoraciones positivas y negativas (oposiciones y valores) de las demás personas.

Es por ello que, en función de coincidir con las condiciones de valor, impuestas al sujeto por su ámbito social, el individuo en cierto modo sacrifica deseos propios y pierde espontaneidad al "regirse" por patrones socioculturales e interpersonales que niegan su naturaleza. Entonces, el individuo adopta valores, creencias y conductas ajenas (como si realmente fueran suyos) para sentirse aprobado por los otros a través del proceso de 
introyección, lo cual conduce a una situación de incongruencia entre sus verdaderas necesidades, sentimientos y deseos (que no desaparecen) y el conocimiento (distorsionado) que se tiene de ellos en el marco de su simbolización consciente.

Esto - dice Rogers- es la alienación fundamental del hombre. No ha sido fiel a sí mismo, a su proceso natural y organísmico de valoración de la experiencia. Al contrario, para preservar la atención positiva del otro, ha llegado a falsear algunos valores de su experiencia y a percibirla solamente a través del mérito que otro les atribuye. Sin embargo, esto no ha sido algo consciente, sino que ha respondido a un desarrollo natural y trágico durante la infancia. (Rodríguez Echeverría y Velasco Lafarga, 2000: 216)

Frecuentemente, el sujeto vive con una incisiva discrepancia entre su concepto de sí mismo (distorsionado por introyecciones sociales) y su "yo-real". Tal discrepancia se expresa también en el comportamiento cotidiano del sujeto, lo cual disminuye el potencial de plenitud del individuo y se conoce con el término de incongruencia, cuyo resultado -en el pensamiento rogeriano- es la frustración, las emociones negativas y/o el comportamiento antisocial.

Para Rogers, por lo tanto, los sujetos que presentan dificultades o problemas de personalidad en el fondo necesitan una reintegración o reencuentro consigo mismos. En esta lógica:

El camino del desarrollo hacia la maduración psicológica y el camino de la terapia consisten en deshacer esta alienación del funcionamiento humano y en disolver las condiciones de valor permitiendo la construcción de un yo congruente con la experiencia y la restauración de un proceso organísmico unificado de valoración de la experiencia. (Rodríguez Echeverría y Velasco Lafarga, 2000: 216)

En efecto, en la teoría y la práctica rogeriana, se hace necesario un incremento de la atención positiva e incondicional para con el sujeto en función, precisamente, de que pueda recuperar la oportunidad de apreciarse consciente e incondicionalmente, aceptar sus experiencias totales y sus valoraciones reales, y así lograr un acercamiento entre su autoconcepto y su experiencia. En palabras de Rogers (2000 [1959]: 235), "[1]a adaptación psicológica existe cuando el concepto de sí mismo es tal que todas las experiencias sensoriales y viscerales del organismo son o pueden ser asimiladas en un nivel simbólico, en relación compatible con el concepto que tiene de sí”. Desde luego que semejante atención positiva incondicional, como veremos más tarde, resulta muy cuestionable. 
Rogers (2000 [1959]: 204) afirma que el comportamiento humano "es básicamente el esfuerzo intencional del organismo por satisfacer sus necesidades tal como las experimenta, en el campo tal como lo percibe". Tales necesidades se elaboran y canalizan a través de un condicionamiento cultural, de carácter secundario, e implican siempre una dimensión presente y actuante. Según Rogers (ibidem), "la conducta no es 'causada' por algo que sucedió en el pasado". Por cierto, en este proceso la emoción es un elemento concomitante al comportamiento. Según Rogers, sucede también que a menudo el sujeto asume papeles, funciones provenientes de su contexto interpersonal y social, que en el fondo no desea y por tanto no son auténticos para él. Así, la persona se siente "atrapada" entre sus necesidades reales y las expectativas que desde fuera se han depositado en ella respecto al papel que debe desempeñar. En tal situación se fractura la identidad personal, se vive inestablemente y se presenta la inseguridad. Ante esta incongruencia o incompatibilidad entre la experiencia real y la simbolización consciente marcada por las condiciones de valor, surgen en el sujeto procesos de defensa

que consisten para el individuo en negarse de diferentes modos a percibir las partes de la experiencia que ponen en peligro su concepto del yo, tal y como se construye en sus relaciones con el otro. La experiencia del individuo que no es simbolizada de manera consciente, no deja de existir y se traduce cada cierto tiempo en su comportamiento, creando así una amenaza permanente para la estructura del yo y una situación de ansiedad. (Rodríguez Echeverría y Velasco Lafarga, 2000: 216)

En la concepción rogeriana, toda esta circunstancia de escisión de la individualidad, por lo general, no se concientiza en primera instancia sino que se detecta a nivel de subcepción (o prepercepción), lo cual significa que aunque esa persona no haya simbolizado conscientemente aún la experiencia que vive (porque se distorsione o se niegue), sí puede tener "una respuesta orgánica fisiológica evaluadora y discriminativa ante la experiencia que puede preceder a la percepción consciente de tal experiencia" (Rogers, 2000 [1959]: 227). Es decir, que ante una situación que provoca en el sujeto un conflicto entre su autoconcepto y su experiencia (aun y cuando ese sujeto distorsione o niegue esa experiencia para no contrariar su imagen del yo) y aunque tal situación no se haya codificado conscientemente, el sujeto se ve afectado por ella a nivel de subcepción, con lo cual sobreviene ansiedad, sensación de amenaza, vulnerabilidad y descontrol. Rogers continúa:

Este tipo de hallazgo parece apoyar nuestra hipótesis clínica y teórica de que el individuo puede negar las experiencias a la consciencia sin haber sido nunca consciente 
de ellas. Hay al menos un proceso de "subcepción" [...] Esto proporciona una posible descripción básica de la manera en que se puede impedir la simbolización exacta y la consciencia de las experiencias que se sienten amenazadoras. Aquí también podemos tener una base para describir la ansiedad que acompaña a numerosas desadaptaciones psicológicas. La ansiedad puede ser la tensión que muestra el concepto organizado de sí mismo, cuando estas "subcepciones" indican que la simbolización de ciertas experiencias sería destructiva para la organización (2000 [1959]: 227).

Se corrobora entonces el planteamiento clave de que la inadaptación psicológica y las dificultades comportamentales del sujeto para satisfacer sus necesidades, se producen frecuentemente cuando la persona rechaza de la consciencia experiencias significativas, es decir, experiencias que no son simbolizadas, organizadas e incorporadas plenamente a la estructura de su sí mismo, con lo cual se genera tensión psicológica potencial. Por el contrario, la adaptación y el desarrollo psicológico se facilitan cuando el sujeto presenta un concepto de sí mismo que asimila o puede asimilar todas las experiencias - por divergentes que sean- en un nivel simbólico, en relación compatible consigo mismo. Por tanto, se trata de que el sujeto logre descubrir y expresar su autenticidad, aun dentro de los papeles y prescripciones que su mundo social e interpersonal asigne.

Surge entonces la cuestión acerca del procedimiento psicoterapéutico. Según este modelo teórico, ¿qué es necesario hacer para que la persona logre tomar consciencia de aquellos ámbitos de su experiencia no incorporados a la estructura de su sí mismo? Para Rogers, la respuesta implica una dimensión más actitudinal que propiamente técnica. En principio, en el encuentro terapéutico se trata de promover la apertura en la expresión afectiva del sujeto y auxiliarlo en el paulatino abandono de sus defensas psicológicas, para lo cual es imprescindible crear una atmósfera de seguridad y de respeto a través de la aceptación incondicional del sujeto como persona. Además, habrá que evitar sugerencias u órdenes explícitas puesto que ellas involucran determinada manipulación del terapeuta respecto al sujeto. Esto es precisamente la llamada actitud no directiva, en tanto existe una renuncia consciente por parte del terapeuta a orientar a la persona hacia alguna dirección explícita en su comportamiento, ideas o emociones. En este sentido, Rogers utilizó después la expresión "centrarse en la persona" para designar una noción más amplia del proceso. La aceptación incondicional en la teoría rogeriana implica una consideración positiva hacia el sujeto (que ha de verse como un ser humano inmerso en dificultades), aun cuando esa persona pueda considerarse aborrecible por los cánones o estándares socioculturales generalizados. Al respecto, Nicholas S. Dicaprio (1993:326) afirma: 
El individuo merece una consideración positiva, aun cuando en el sentido social no la merezca [...] El terapeuta centrado en el cliente da su consideración positiva, no porque la persona la merezca sino porque la necesita. Cada persona tiene una necesidad genuina de tal consideración positiva.

No obstante, es preciso señalar que la actitud no directiva, según la posición de Rogers, no debe confundirse con la permisividad indiferente, la pasividad o una conducta irresponsable del terapeuta. Es decir, la actitud no directiva fracasará terapéuticamente si el psicólogo no asume un compromiso ético profesional y personal con el sujeto, en función del proceso. Así, el terapeuta rogeriano, de acuerdo a este esquema, ha de ser receptivo, centrarse en las vivencias y emociones del sujeto y no tanto en los acontecimientos que evoca, interesarse más en la persona que en el problema, respetarla, expresarle su consideración real y promover la comunicación sin hacer revelaciones o interpretaciones. De hecho, Rogers plantea explícitamente tres condiciones definitorias de la actitud no directiva: la aceptación incondicional, el estado psicológico de congruencia en el terapeuta y la comprensión empática (Rogers y Kinget, 1972 [1965]).

En el orden estrictamente técnico, la intervención no directiva implica la utilización de recursos psicoterapéuticos abiertos tales como la clarificación; la paráfrasis, las técnicas de reexpresión o respuestas reflejo, el resumen, entre otros (Rodríguez Echeverría y Velasco Lafarga, 2000; Rogers, 2000 [1959]; Rogers y Kinget, 1972 [1965]; Zaldívar, 1991). En definitiva, se busca que el sujeto reorganice su campo perceptivo, logre la liberación emocional y pueda configurar un autoconcepto compatible con sus experiencias, es decir, que se acepte a sí mismo en todas sus facetas. Para Rogers, el proceso psicoterapéutico implica una trayectoria continua en la que, no obstante, se pueden distinguir dos grandes fases (Rogers y Kinget, 1972 [1965]). En primer lugar se presenta la fase de desorganización (incongruencia interna del sujeto) en la cual la persona se mueve psicológicamente desde la rigidez y el posible rechazo a la elaboración de su experiencia, hacia la paulatina fluidez y facilidad de la persona en la expresión simbólica de su mundo afectivo -todavía insuficiente, pero poco a poco en vías de aceptación-. En segundo lugar se presenta la fase de reorganización (congruencia interna del sujeto) en la que el individuo se orienta ya hacia un relajamiento de sus esquemas y un discurrir más libre de sus sentimientos, hasta la libertad experiencial y afectiva expresada desde un sentido personalizado, auténtico y presente de sí mismo. Así, por lo general, el sujeto primero describe, luego explora, posteriormente analiza y por último reorganiza sus contenidos subjetivos, en un acto de integración personal. La reorganización del concepto de sí mismo 
se orienta a la revalorización individual y a la autonomía. La persona se abre a sus experiencias en toda su variedad. El sujeto descubre que "puede definirse a sí mismo partiendo de su experiencia, en lugar de querer imponer a su experiencia una definición de su Yo que rehúse tomar consciencia de los elementos que no cuadran con ella" (Rogers y Kinget, 1972 [1965]: 65). Según Rogers, surge entonces en el individuo la aceptación constructiva, el afecto hacia sí mismo y la creatividad para desarrollar sus potencialidades.

La crítica general más importante que puede hacerse al pensamiento rogeriano se constituye por el modo en que se adscribe a un proceso constante de psicologización de la vida (Parker, 2010). El esquema rogeriano, centrado en los aspectos psicológicos de "la persona", no asume ni reflexiona con profundidad ni con especificidad el conjunto de determinaciones propias de los contextos económicos, sociales, culturales o lingüísticos que marcan de muchas maneras los diversos desarrollos psicológico-personales de los individuos. El dispositivo psicológico-terapéutico genera la promesa implícita de una transformación personal cualquiera, vinculada fundamentalmente a la posibilidad de que el sujeto haga consciencia de los problemas que tiene consigo mismo (sin abrir ningún cuestionamiento a las líneas prescriptivas generadas por los contextos económico-sociales y políticos de las relaciones de poder dominantes en un momento histórico concreto), lo cual, en la práctica, pasa básicamente por ser capaz, con la ayuda terapéutica, de incorporar determinadas formas de lenguaje y de comportamientos individuales que implican determinadas acciones y vocabularios de funcionalidad en las interacciones sociales.

Así, a partir de diferentes experiencias de trabajo con el "enfoque centrado en la persona”, Rogers (1980 [1977]: 96) llega a plantear que

existen modelos para manejar constructivamente casi cualquier variedad de tensión intergrupal, ya sea que hablemos de diferencias religiosas o de rencores basados en la lucha de la pobreza contra la riqueza o desconfianzas fincadas en diferentes costumbres culturales o de la rabia almacenada que surge de la discriminación racial, o de odios a muerte que tienen siglos de existir y que incluyen varios de estos elementos, no carecemos de conocimientos ni de experiencia para usar habilidades interpersonales que ayuden a resolver estas tensiones.

La reflexión y la práctica terapéutica rogeriana promueven, además, un cierto tipo de ordenamiento ideo-afectivo que presupone y reivindica en el individuo una presunta congruencia interna entre pensamientos, sentimientos y acciones, con lo cual se encauza al sujeto hacia la configuración de cierto modo de ser persona en el que habrán de excluirse expresiones 
tales como el enfado con la vida, los afectos pasionales, la indolencia o la exageración de la alegría, por su presunta condición alienante o indeseable. Así, de manera tácita se alimenta la concepción ideológica de un ciudadano sin exabruptos, deseable, equilibrado, constructivo, feliz y estable en sus relaciones con los demás y con las instituciones (tal como se puede pensar del "buen samaritano"):

Un individuo que está intentando vivir su vida con un estilo centrado en la persona genera una política de las relaciones familiares y de las relaciones matrimoniales o de compañeros que es drásticamente diferente a la del modelo tradicional. El niño es tratado como una persona única, digna de respeto, con el derecho a evaluar su experiencia a su manera, con amplios poderes de elección autónoma (Rogers, 1980 [1977]: 19).

La vocación no directiva de Rogers se asocia a una actitud que permite a uno u otro sujeto la apertura y expresión de sus formas de percibir y sentir lo que le suceda; esto suele implicar un sentimiento liberador o cierta sensación de desahogo en el individuo que, sin embargo, tendrá un carácter estrictamente paliativo porque no conlleva la indagación, el análisis o la atención de las causas o problemas de fondo ni sus conexiones sociales y políticas complejas. "Abrir" los sentimientos propios para sentir alivio, presupone asumir el precepto de que los problemas del sujeto radican en su dimensión afectiva (o cognitivo-afectiva) y no en las relaciones sociales y en las condiciones de vida material, económica, laboral, política y/o cultural que sobrepasan al sujeto mismo y lo marcan permanentemente de muchas maneras.

En todo caso, la concepción psicoterapéutica rogeriana, a pesar de su no directividad, logra moldear las emociones y promover su manifestación personal en términos de una pretendida autenticidad que no contempla, en su estatuto complejo, los contextos axiológicos, lingüísticos, afectivos e históricos diferentes e irrepetibles de cada sujeto en cuestión. Así, a partir de un contexto muy delimitado de sus experiencias terapéuticas y de grupos (propias de ciudadanos, discursos y prácticas pertenecientes a países, instituciones y ámbitos particulares de cierto desarrollo socioeconómico del mundo capitalista reciente), se propende a generalizar, sin mayor detenimiento, los componentes psicológicos de lo bumano.

En otras palabras, la teoría de Rogers asume un carácter esencialista en sus conceptos en tanto despliegan, más o menos deliberada y sutilmente, una pretensión trascendente y universal. Es decir, que a las categorías y reflexiones de esta concepción (aplicables seguramente al sujeto occidental, norteamericano o europeo, de clase media más o menos acomodada en los entretejidos económicos del capitalismo reciente, predominantemente 
blanco, heterosexual, consumidor y adscrito a subconjuntos familiares e institucionales relativamente estables) se les otorga un valor psicológico per se, al margen de los entramados socioculturales concretos desde los cuales han surgido y de las condiciones ideológicas y políticas que lo permiten.

El modelo teórico y la praxis terapéutica de Rogers implican, más o menos sutilmente, una especie de coacción no directiva; es decir, una coacción no directa, explícita o abiertamente prescriptiva; pero sí una coacción indirecta que funciona mediante los efectos del proceso mismo, vinculados al concepto y la aceptación paulatina por parte del sujeto de los modos deseables o esperables de ser (tales como la "autenticidad", la "congruencia", el "reconocimiento de sí mismo", la "toma de consciencia de las relaciones propias", la "disposición al cambio" o la "asunción del ejercicio autorreflexivo", etc.) en la convivencia y las interacciones, dentro de los espacios sociales y familiares. En todo caso, se trata de una coacción quizá no sobre el individuo visible y sus decisiones inmediatas, sus sentimientos específicos, valores e ideas en un momento dado; pero sí una coacción sobre las decisiones, sentimientos, valores e ideas que resultan deseables para el modelo mismo.

Por otro lado, la psicología humanista de Rogers juega el papel de algo así como una práctica espiritual biempensante de carácter no religioso. En este sentido, Ian Parker (2010: 166) afirma:

La psicología tiene una versión modesta de la figura holística y equilibrada del gurú que habitualmente vive allende y que ofrece clarividencia a los seguidores y visitantes. Así se aprecia cuando la psicología occidental propone a su hombre sabio en la figura de Carl Rogers, tan agradable como Mahatma Gandhi, y con suficiente empatía hacia las situaciones difíciles de los otros, lo que le asemeja a un santo moderno. No obstante, existen graves problemas con esta psicología "humanista", que juega el papel de una psicología espiritual en el marco de la tradición psicológica occidental y en las aproximaciones colindantes del asesoramiento psicológico y la psicoterapia, que la psicología ha procurado registrar como propias.

Adicionalmente, el modelo rogeriano, incluso en sus variantes de trabajo grupal (Rogers, 2001 [1970]), se concentra en la "persona aislada e individualizada" y "encuentra la manera de tratar ese estado de aislamiento como si fuera una virtud" (Parker, 2010: 167). El sujeto en su individualidad, ante la situación de "incongruencia" e "infelicidad" que-gracias al procedimiento psicoterapéutico- descubre respecto a su propia vida, deberá "percatarse de que la respuesta se encuentra en su interior" (ibidem); lo cual, según la fuerte crítica del propio Parker (ibidem), constituye "la mayor patraña de la sociedad occidental individualista, la cual, si bien reconoce que las 
relaciones con los otros son cruciales para llegar a ser nuestros verdaderos yoes, asegura que podemos encontrar la claridad sin transformar la naturaleza socialmente estructurada de esas relaciones”. En otras palabras, a contrapelo de la motivación psicoterapéutica de Rogers, deberá comprenderse que no se puede pretender cambiar de manera profunda el texto subjetivo del individuo al margen del contexto social y político en donde ese individuo es generado, como si el sujeto fuese la gran figura que debe tratarse y las condiciones de la materialidad estructural, social e interactiva de ese mismo sujeto fuese únicamente su paisaje de fondo.

Para el modelo rogeriano, la expresión de las emociones individuales constituye un momento beneficioso y deseable, pero solamente en tanto se constituye como una posibilidad, que juega en términos del funcionamiento social aceptable y de articulaciones de sentido interactivo dirigidas a la estabilización de la convivencia; todo en aras de construir modos de relación productiva que resulten, en lo posible, positivas y amigables para todos, y que permitan al individuo "encontrar" su lugar y su equilibrio en el mundo social sin tener que plantearse, de manera estratégica o radical, el cambio, la consciencia crítica, el combate o la transformación política de ese mundo social.

Así, la perspectiva y el quehacer terapéutico del modelo evidencia su colusión implícita con el orden sociofuncional de las relaciones de poder vigentes (Daza, 2006; García Rodríguez y López Raventós, 2011; Rose, 1996) y, desde luego, también en consecuencia con los marcajes de una moralidad dominante. Queda claro que el modelo resulta políticamente útil al sistema socioeconómico imperante, porque el conjunto de preceptos que detenta contribuye a mantener cualquier circunstancia problemática o conflictiva del sujeto "dentro de los márgenes de lo personal y lo individual" (Parker, 2010: 168).

En todo caso, más allá del presunto respeto y la "aceptación incondicional" de las personas que participen en la experiencia no directiva, lo que se promueve con mayor alcance es el proceso de uniformar, aplanar, normalizar subjetividades hacia un modelo de gestión de las realidades sociales, ideológicas y afectivas que resulte deseable y muy funcional para el sistema económico y político que lo sustenta, y para las instituciones y aparatos que garantizan su reproducción. En efecto, la actitud no directiva de Rogers promueve la aceptación y la empatía respecto a las particularidades del individuo que participa en el proceso psicoterapéutico, pero todo bajo un modelo de relación implícito, previamente concebido y de carácter vinculante, que ofrece el marco de saberes y poderes instituido, sólo al interior del cual el sujeto puede hablar y puede llegar a "ser él mismo". 
Además, la concepción rogeriana promueve y subraya, tácita o explícitamente, una concepción de "lo positivo" en la persona y se puede considerar una de las precursoras de la llamada "psicología positiva" desarrollada en Norteamérica (Seligman, 2002, 2003). Sin embargo, dicho énfasis en lo positivo de la persona no significa que los terapeutas no directivos dejen de evaluar o valorar aspectos en el individuo calificables como "negativos" o que se deje de pensar en términos de "patologías" o de aspectos políticamente despreciables del sujeto (como podrían ser el racismo y el machismo), lo cual, aparte de implicar una inevitable actitud de hipocresía en el terapeuta -porque como dice Parker (2010: 168): "por buena fe que tenga no puede estar de acuerdo en todo lo que dice el cliente"- lo que genera es que se utilicen eufemismos para describir tal conjunto de situaciones; es decir, que se produzcan lenguajes "positivos", "respetuosos", "reflexivos" (que a su vez, por cierto, pretenden instalarse silenciosamente en el discurso del propio sujeto como cliente) para poder hablar sobre el sujeto y sus problemas de modo "constructivo", y enfatizar un posible encauzamiento y una posible superación de su situación adversa o conflictiva hacia su propia aceptación y ulterior "bienestar", preferiblemente en armonía con las prescripciones, normas y valores de convivencia dominantes en su propio contexto social y político. En el fondo, una vez más ocurre que "estos psicólogos promueven obtener el mayor provecho posible de unas condiciones sociales demoledoras al sobrevalorar y ensalzar la capacidad de los individuos para prosperar por sí mismos. Es probable que de esta manera los psicólogos se sientan mejor consigo mismos, si bien esta vía no supone un profundo cambio ideológico en la disciplina" (ibidem).

Puede afirmarse que el modelo teórico-práctico de Rogers marca de antemano la lógica interpretativa de la subjetividad de los clientes, acorde con los preceptos que lo constituyen. Todo cliente termina siendo leído en términos del código rogeriano mismo. Con ello se reivindica el intento de retomar la "perspectiva interior" del cliente y el poder lograr una "comprensión empática" de lo que se dice, para conocer la verdad del individuo ("su verdad" de las cosas) sin abordar, por cierto, el cómo han llegado a pensar, sentir y actuar así, o cómo ha llegado a ser la persona que es, bajo qué contextos y condiciones de predeterminación social, económica, política y cultural.

\section{Consideraciones finales}

La perspectiva del desarrollo en la concepción rogeriana se relaciona con la posibilidad de que el sujeto reconozca y acepte el cúmulo de experiencias propias en función de lograr la conversión al "yo real” y, consecuentemente, a una especie de plenitud funcional. Esto significa que la persona podrá 
llegar a actuar de manera "congruente", "auténtica" y "autónoma", pero sin lograr nunca dejar de someterse, en alguna medida o de una u otra forma, a los preceptos de vivir acorde a los vectores discursivos y prácticos impuestos por las relaciones de poder dominantes. Dichos vectores pueden incluir, por ejemplo, cuidar los límites de ciertas conductas formales o formas de relación, gestionar unas u otras apariencias, obligaciones institucionales, expectativas paternas o mandatos socioculturales. Una cosa es que cualquier individuo, llegado cierto momento de su madurez, pueda y quizá deba asumir orientaciones propias y cierta responsabilidad personal ante los escenarios de la vida social, con toda la carga, frecuentemente dolorosa, de la obtención de su autonomía, e incluso, esperar con ello cierto momento de satisfacción personal; pero otra cosa es que, a partir de un ejercicio rampante de psicologización, se pretenda que sólo por la supuesta fuerza personal e interior del sujeto, por ejemplo su tendencia a la actualización, se logre la plena autorrealización, la felicidad y el éxito social al tiempo que se niegue o se ignore el papel prescriptivo de límites o de posibilidades predeterminadas que, desde una condición estructural, pueden jugar las condiciones materiales, socioeconómicas, políticas, lingüísticas y culturales que rodean a ese sujeto y lo van troquelando a lo largo de la propia convivencia social.

En justicia y en aras de matizar la crítica que acabamos de formular, debe mencionarse que Rogers destaca la noción de proceso de vida como una dimensión que involucra la creatividad, la expresión espontánea, la plasticidad emocional y una "orientación dinámica y cambiante hacia la vida" (Dicaprio, 1993:337) que se opone a la noción de estado (fijo) de "funcionamiento adecuado". Desde luego, esta noción resulta muy interesante, pero al final, sucumbe de nuevo a la consigna de la psicologización. Para Rogers, el proceso de vida tendrá carácter experiencial y habrá de romper con las estructuraciones estáticas. La verdadera actualización, según se aclara, no consistirá en mantener una situación de "virtud" o "felicidad" constante, ni un equilibrio u homeostasis concebida como meta idealizada del sujeto. Por el contrario, la actualización individual implicaría el proceso de participación cotidiana e interactuante del sujeto en la construcción de los sentidos y directrices de su vida. Presupondría avalar las posibles contradicciones, tensiones o desilusiones que el mismo proceso pueda traer, aunque siempre delineando una disposición de libertad interior, de movilidad y de apertura a la experiencia. Vivir en el proceso de la actualización significaría también despojarse de las barreras defensivas en el establecimiento y desarrollo de las relaciones interpersonales. Se podrían excluir las máscaras psicológicas porque el sujeto no necesitaría ser diferente de sí mismo. Según esta lógica, el momento de la psicologización se constituye en que las valoraciones y los 
comportamientos del sujeto surgirían de acuerdo a una codificación propia de la experiencia, a la cual, en la visión rogeriana, no se le impondría ningún orden artificial o prescriptivo de carácter externo. Es decir, la sola libertad experiencial, precisamente, le otorgaría al sujeto la prerrogativa de descubrirse y expresar sus vivencias, pensamientos y deseos tal como él es capaz de sentirlos independientemente de su conformidad respecto a normas y preceptos sociales y morales dominantes en su ambiente (Rogers y Kinget, 1972 [1965]). Dicha libertad experiencial estaría limitada únicamente, al menos en determinado momento, por las normas jurídicas del lugar donde esa persona radique. Las experiencias tendrán que fluir sin recibir cargas de significación inhibitoria o enjuiciadora de carácter ajeno al sujeto.

En este sentido, la confianza en aquella "sabiduría organísmica" y en el "sentido orgánico" (experiencial) del individuo es tan grande, que estará por encima no sólo de las elaboraciones intelectuales de ese sujeto, sino incluso del reconocimiento de los ámbitos productivos y prescriptivos de las relaciones de poder vigentes y de sus plataformas materiales y organizativas establecidas socialmente. Al respecto, señala Rogers (apud Dicaprio, 1993: 339): "cuando una actividad se siente como si fuera valiosa o que vale la pena hacerla, sí vale la pena hacerla [...] He aprendido que mi sentido orgánico de una situación es más confiable que mi intelecto”. En resumen, para Rogers, cuando una persona es congruente con su organismo total, lo cual incluye los aspectos intuitivo y sentimental, prácticamente estará predestinada a la realización plena y a la convivencia feliz; sin importar demasiado las condiciones de vida social y las relaciones de poder que establecen las pautas de desarrollo posible. En efecto, lo que se logra evidentemente con esta postura es convertir el dispositivo teórico y psicoterapéutico rogeriano en un recurso y una herramienta más al servicio de las propias relaciones de poder instituidas, de saberes naturalizados y extendidos, y de un statu quo de los órdenes sociales que no se cuestionan en lo político, para depositar en los ámbitos estrictamente psicológico-personales cualquier opción de felicidad y desarrollo. A tal grado es así, que en la visión rogeriana la integración y la plenitud psicológica no deberán asociarse, a la complacencia o al exclusivo disfrute del sujeto respecto a sus acciones o condiciones existenciales, sino a la variedad y a la resignificación experiencial permanente, a pesar de que tal circunstancia promueva también (cómo no) la situación de convivir con la incertidumbre, el fracaso o el miedo como espacios subjetivos presentes en el propio decursar de la vida.

Resulta interesante también que la perspectiva humanística rogeriana reivindicará la idea del autocontrol y de la adecuada autorregulación del sujeto, lo cual habrá de constituirse, tácita o explícitamente, en una de las 
metas a lograr por parte del sujeto-cliente, quien a partir de la concientización de sus problemas personales y en relación con sus opciones de funcionalidad social esperable, participa en algún proceso psicoterapéutico. En este sentido, en su libro El poder de la persona, Rogers (1980 [1977]: 63-64) afirma: "Yo pienso que al haber rehusado a utilizar la coerción o a dirigir, yo he estimulado el aprendizaje, la creatividad y la autodirección. [...] Yo he promovido la autonomía, la responsabilidad propia y la madurez al estimular la habilidad de las gentes para evaluarse a sí mismas". En el modelo rogeriano no se tratará de ejercer una ruptura personal y política radical o consistente a respecto de los eventuales contextos sociomateriales y axiológicos de explotación, precariedad, discriminación o abuso de poder en los que viva el sujeto, ni tampoco de organizarse colectivamente para la reactivación de la resistencia social en busca de cambios en las estructuras sociales que generen mayor justicia, equidad o desarrollo social real, sino solamente de ser capaz, como individuo, de configurarse y readaptarse psicológicamente en la dirección de un autogobierno y de la consecución de un estilo de vida propio, de carácter acrítico, que se relacione flexible y dócilmente con las condiciones sociales, económicas y políticas imperantes. Dicho de otra manera, se trata de promover el objetivo de instaurar el eje de la funcionalidad institucionalizada en el sujeto, de tal modo que simultáneamente se reivindique un sentido subjetivo de autenticidad y libertad en sus decisiones, reflexiones, afectos y acciones.

Revisado por José Morales

\section{Referencias bibliográficas}

Daza, Óscar (2006), "El paradigma de control social en los orígenes de la psicología", in José Luis Romero Cuadra; Rafael Álvaro Vázquez (coords.), Antipsychologicum. Bilbao: Virus, 27-42.

Dicaprio, Nicolas S. (1993), Teorías de la personalidad. México: McGraw-Hill.

García Rodríguez, Raúl Ernesto; López Raventós, Cristian (2011), "Las prácticas interventivas del complejo psicológico: breve análisis crítico para el mundo de hoy", in Luz María Lepe Lira; Adriana Sánchez Martínez (coords.), Perspectivas críticas de la Psicología. México: Morevallado, 23-41.

Parker, Ian (2010), La psicología como ideología. Contra la disciplina. Madrid: Catarata. Traducido por Ángel Gordo.

Rodríguez Echeverría, Gerardo; Velasco Lafarga, José Luis (2000), "Terapia rogeriana”, in Celedonio Castanedo (ed.), Seis enfoques psicoterapéuticos. México: El Manual Moderno, 252-258. 
Rogers, Carl Ransom (1980), El poder de la persona. México: El Manual Moderno. Traducido por Salvador Moreno López [ed. orig. 1977].

Rogers, Carl Ransom (1997), Psicoterapia centrada en el cliente. Práctica, implicaciones y teoría. Barcelona: Ediciones Paidós Ibérica. Traducido por Silvia Tubert [ed. orig. 1951].

Rogers, Carl Ransom (2000), "Una teoría de la personalidad y de la conducta”, in Fernando González; Gustavo Pineda (comps.), Selección de lecturas de personalidad. La Habana: Ministerio de Educación Superior, 188-215 [ed. orig. 1959].

Rogers, Carl Ransom (2001), Grupos de encuentro. Buenos Aires: Amorrortu. Traducido por Ana María Payró de Bonfanti [ed. orig. 1970].

Rogers, Carl Ransom (2007), Terapia, personalidad y relaciones interpersonales. Buenos Aires: Nueva Visión. Traducido por Antonio Carmona y Ofelia Castillo [ed. orig. 1959].

Rogers, Carl Ransom (2011), El proceso de convertirse en persona. México: Editorial Paidós Mexicana. Traducido por Liliana R. Wainberg [ed. orig. 1961].

Rogers, Carl Ransom; Kinget, G. Marian (1972), Psicoterapia y relaciones bumanas. Madrid: Alfaguara. Traducido por Mercedes Valcarce [ed. orig. 1965].

Rogers, Carl Ransom; Rosenberg, Rachel L. (1989), La persona como centro. Barcelona: Herder. Traducido por Diorki [ed. orig. 1977].

Rose, Nikolas (1996), Inventing Ourselves: Psychology, Power and Personhood. Cambridge: Cambridge University Press.

Seligman, Martin E. P. (2002), La auténtica felicidad. Barcelona: Vergara. Traducido por Mercè Diago y Abel Debritto.

Seligman, Martin E. P. (2003), "Positive Psychology: Fundamental Assumptions”, The Psychologist, 16, 126-127.

Zaldivar, Dionisio (1991), Teoría y práctica de la psicoterapia. La Habana: ENPES.

\section{Areli Vázquez Arellano}

Facultad de Psicología, Universidad Michoacana de San Nicolás de Hidalgo

Gral. Francisco Villa 450, Dr Miguel Silva González, 58110 Morelia, Michoacán, México

Contacto: arelli-vazquez-arell@hotmail.com

ORCID: https://orcid.org/0000-0001-6893-7519

\section{Raúl Ernesto García Rodríguez}

Facultad de Psicología, Universidad Michoacana de San Nicolás de Hidalgo

Gral. Francisco Villa 450, Dr Miguel Silva González, 58110 Morelia, Michoacán, México

Contacto: raulgarciar@gmail.com

ORCID: https://orcid.org/0000-0001-6864-4134 
Recibido: 13.02.2020

Aceptación comunicada: 04.06.2021

https://doi.org/10.4000/rccs. 12053

\section{The Non-Directive Vocation of Carl Rogers: Theory, Psychotherapy and Relations of Power}

In this article we offer a brief presentation and critical review of some of the most important ideas in the thought of Carl Rogers in relation to his conception and practice of psychotherapy. Through an interpretative exercise supported by the premises of critical psychology, but with no pretension of stating absolute affirmations, it questions several postulates of the Rogerian perspective in its historical-theoretical context and its consubstantial linkage to the relations of power that are assumed and reproduced in its development. In addition, it discusses the exercise of psychologization present in the Rogerian apparatus, its political character, and its tendency towards an acritical harmonization of social relations.

Keywords: Carl Rogers; critical thinking; psychotherapy; power relations; social relations.

\section{La vocation non directive de Carl Rogers : théorie, psychothérapie et relations de pouvoir}

Dans cet article, on procède à une brève présentation et à une révision critique de quelques-unes des idées les plus importantes de la pensée de Carl Rogers concernant sa conception et sa pratique de la psychothérapie. Ainsi, à partir d'un exercice interprétatif soutenu par des prémisses de la psychologie critique et sans prétendre faire des déclarations absolues, on remet en question plusieurs postulats de la perspective rogérienne dans son contexte historico-théorique et dans son lien consubstantiel avec les relations de pouvoir que présupposent et se reproduisent dans son développement. Dans tous les cas, on aborde également l'exercice de psychologisation présent dans le dispositif rogérien, son caractère politique et sa tendance à l'harmonisation acritique des relations sociales.

Mots-clés: Carl Rogers; esprit critique; psychothérapie; relations de pouvoir; relations sociales. 